\title{
The Research on Mobile Payments in the Theory of Electronic Commerce
}

\author{
Yang Hao \\ School of Computer \\ Shengyang Aerospace University \\ Shengyang China
}

\author{
Gao Siyu \\ School of Economic and Management \\ Shenyang Aerospace University \\ Shenyang, China \\ e-mail: 760053198@qq.com
}

\begin{abstract}
China has entered the 21st century of economic globalization. As the market economy grow rapidly and the opening up further deepens, huge changes have taken place in China's electronic commerce market and the main payment form. In the era of $3 G$, based on the application of computer network and electronic tools, electronic commerce is the mobile electronic commerce system supported by mobile communication device and wireless Internet access technology. With the on-line promotion of 3G, China's telecommunications industry structure will have profound changes, and electronic commerce activities will also become more and more frequent. In this case, as the core of electronic commerce, mobile payment technology and applications will also undergo rapid development. In the mobile electronic commerce era, the mobile payment will increasingly highlight the trends and features of network technology mobility, market-oriented operation pattern, service function diversification, consumer application socialization and industrial chain link.
\end{abstract}

Keywords-Electronic Commerce; Mobile Payment; Mobile Payment Technology; Innovation

\section{INTRODUCTION}

In recent years, the rapid development and popularity of communication technology are profoundly changing people's lifestyle. As an advanced way of electronic payment, Mobile payment is constantly developing throughout the world, which is a potential industry. However, the profound application of mobile payment is still in the preliminary stage in China, and there are many issues to be solved. Researches on the industrial chain, operation mode and technological implementation methods of mobile payment have important theoretical and practical significance for the development of China's mobile payment industry.

\section{Mobile Payment OPERATING PRINCIPLE AND MODE ANALYSIS IN ELECTRONIC COMMERCE}

\section{A. Analysis on Mobile Payment Operating Principle in Electronic Commerce}

It can be divided into remote payment and near field payment by the payment location. Payment and technological implementation method differ in varied locations.

Remote payment refers to the deduction request proposed to the back-end accounting system through wireless network by using SMS, WAP and other technologies and completion of the payment action.

Near field payment means that the mobile phone should support the RFID, infrared and Bluetooth to implement the local communications of mobile phone and other intelligent terminals, including vending machines, POS terminal and complete the payment.

The main implementation technologies of remote payment: SMS, WAP, IVR, K-java/BREW, USSD, etc; the main implementation technologies of of near-field payment mainly include infrared, Bluetooth, RFID, NFC, etc.

Credit Card Payment: Under this category, the forerunner is no other than Herald. Currently the successful imitation examples include Lacarra and China UnionPay. By using mobile readers and coordinating with the mobile phones, its users (consumers or businesses) can match credit card spending in any $3 \mathrm{G}$ or Wi-Fi network status, which makes consumers and businesses make payment and receipt in any places, save the corresponding consumer information, and greatly reduce the technical threshold and hardware requirements of credit card payments.

Application Payment: mobile phone App payment is accompanied by the emergence of modern mobile phones with iPhone and andriod as representatives. Its working mechanism is very simple, which can complete the payment of goods by scanning $\mathrm{QR}$ code.

Operator Billing: the payment mode of operator billing means that the entire payment process is controlled by the operator. The working principles of mobile payment are as follows: the users authorize one-time payment behavior (usually via SMS). Mobile operators will help users handle the entire payment process and draw part of the profits.

Near Field Communication (NFC): NFC technology is a near field communication technology evolved by RFID, and mobile payment is a main function of NFC. NFC mobile payment makes people completely abandon POS and complete the payment process by phone or NFC device at near field.

\section{B. Overview of Mobile Payment Operation mode in Electronic Commerce}

Any industry has its own business mode. Business model is a method of making money and making profits. Strictly speaking, it refers to the business environment, the financial goal to be achieved and internal activities and 
abilities required by the implementation of established financial goal under a given environment. Mobile payment mode can be understood as an operation way of mobile payment industry, providing businesses with services in this way to earn income and survive.

At present, there are mainly three mobile payment business modes: the operation with mobile operator as the main body, the operation with banks as the main body and the operation with the third-party operator as the main body. In different payment modes, all entities in the industrial chain play different roles and assume different obligations.

\section{StRengths of Mobile PAyMent AND PROBlems ANALYSIS IN ELECTRONIC COMMERCE}

\section{A. Strengths and Weaknesses of Mobile Payment in Electronic Commerce}

\section{1) Strengths}

As the product of electronic currency of mobile communications, the mobile payment has much strength, but these strengths determine the prospects of mobile payment.

- Convenient and Easy. Compared with other payment methods, mobile payment is convenient and easy. It only needs to dial the appropriate phone number or send short messages.

- Good Compatibility

- Low payment cost. By using the mobile payment, mobile operators can only charge very low telephone costs or short message costs (or even not receive), and mobile operators mainly gain business income by sharing the profits with businesses or advertisements.

- Good Security. Mobile payment is generally of micro-payment, having low safety requirements. Relative to credit card and other electronic currencies, mobile phone is a common communication tool. Once lost, users can quickly discover and report the loss, will not suffer too much damages.

2) Weaknesses

Meanwhile, the mobile payment has the following significant weaknesses.

\section{a) Immature Technology}

In China, the current main mobile payment is implemented by short message technology. Since this technology adopts very low-speed signaling channel, sometimes it cannot guarantee the real time transaction.

\section{b) Abnormal Phenomena}

As the agency, SP must have quite good qualifications and reputation. However, currently many Chinese SPs do not have the qualifications of SP, and have fraud behaviors towards mobile users and website.

\section{c) Limited Payment Amount}

Mobile payment has another name "micro-payment", meaning it only applies to the businesses of small amount, yet does not apply to bulk trades. It is mainly suitable for the payment of digital electronic commerce products, such as purchasing film currency, prepaid phone cards and ring tones.

\section{B. Mobile Payment Problems in Electronic Commerce}

Although the mobile payment market is featured by large development space and rapid growth, the mobile payment business does not show the development trend as Internet payment, which is mainly reflected by severe disconnection between business volume of mobile payment and client resources of mobile phone. The proportion of mobile payment and online payment is approximately $1: 10,000$, while the proportion of the number of mobile phone users and Internet users in China's is roughly $4: 1$. As the same emerging payment channel, there is a huge contrast of business volume, which is mainly caused by the following aspects:

\section{1) Technical problems.}

The first problem lies in SIM card and STK card. As previously mentioned, due to large memory space, rich menu functions, easy operation and safe trade, STK card is popular among operators. However, SIM cards are widely used in the current mobile phone market, so it is hard to solve the compatibility between cards in mobile payment. The second problem lies in complex operation procedures and operation. The third problem lies in safety issues. The technical safety risks are the biggest problem in China's mobile payment. In China's existing mobile payment methods, bank cards and mobile phone numbers are bounded. Due to restrictions of phone card technology, the information sent is plain code, short messages are transmitted via the public network without encryption function, and it is easy to decipher and intercept the phone number, passwords and other important information.

2) Single service and dull payment contents are the most important reason of unattractive mobile payment.

Currently, the mobile payment is mostly used for the payment of low-value and frequent transactions, such as paying phone bills, water bills, electricity bills, buying lottery tickets and other micro-payments. Various agencies promoted similar mobile payment services. Owing to single and poor service contents, this business is only a supplement for various payment channels. At present, while most mobile phone users do not get used to and distrust the mobile payment, it is rather difficult to widely promote the mobile payment.

3) The interest mechanism of mobile payment is to be established and improved.

Currently, the mobile payment partners differ in the benefit distribution, rights and responsibilities, payment of charges and other aspects, which have affected the promotion of mobile payment to some extent. In particular, the mobile payment has not yet formed a certain business scale, the transaction itself cannot bring high returns to the companies providing mobile payment services.

\section{4) Consumption Habits}

Chinese people's traditional consumption habits have affected the development of mobile payments. Chinese people's dependence on cash transactions is the biggest obstacle to the promote the mobile payment services, and their inherent recognition of consumption patterns and habits slow down the development of mobile payment.

5) High Operating Costs

At present, the bank engaging in this business charge approximately $2 \%$ procedure fee per transaction.

6) Legal Issues 
Currently short message banking fraud incidents have occurred from time to time, and people are quite worried about the safety of electronic payment transactions.

China does not implement adequate promotion of mobile payment and safety education towards users' mobile payment, and there is no established standards and norms, which are factors affecting the large-scale promotion of mobile payment.

\section{Analysis of Mobile Payment Measures in Electronic Commerce}

2008 was undoubtedly a year for the large-scale development of mobile payment. To popularize the mobile services earlier, mobile operators need to note the following issues.

1) Innovate business model and achieve industrial win-win

China's mobile payment industry has the characteristics of long industrial chain, complex cooperative program and high coordination cost, which require that the industry must innovate the business model, realize industrial integration, continuously test and revise during the implementation process, and achieve industrial win-win.

2) Correctly position and actively develop the market

From the aspect of development stage, after experiencing the market orientation period, the main parties of China's mobile payment industry have accumulated relevant experience and key resources, extensively conduct business promotion, and actively implement industrial expansion. In such background, the mobile payment industry should avoid weaknesses, integrate with relevant resources, actively carry out market development, train the user payment habits, and take the road of mobile payment with Chinese characteristics.

3) Strengthen technical support and ensure the transaction safety

Build the first-class safe payment platform and technical support environment to ensure the transaction safety, which is essential smooth development of the mobile payment industry. Among these, encryption and authentication algorithm, the selection of transaction password length and the code size are important factors ensuring the safe efficient mobile payment. In addition, eliminating the user anxiety for the transaction safety, training the users' transaction confidence, enhancing the user's sense of safe payment, and making users personally experience the convenient and efficient mobile payment are also important factors promoting the development of mobile payment industry.

4) Strengthen industry collaboration and avert policy risks

In China, there are all kinds of mobile payment solutions in the market, which are featured by simple technology. However, due to non-uniform industry technological standards, demand of business process restructuring, business development's failure to keep up with technology and especially the uncertain benefit game between mobile operators, banks, special merchants and other parties behind the businesses, the development of China's mobile payment still depends on the joint promotion of the whole industrial chain links, including developers, operators and banks. Therefore, the correct positioning of industry members and the implementation of collaborative business have become a trend.

5) Use new technologies and seize new market

Currently, the application of new technologies is updated very quickly. With the advent of $3 \mathrm{G}$ and even $4 \mathrm{G}$ (the fourth generation mobile communication technology) era, mobile payment providers should pay high attention to the application of new technologies and grasping of new markets.

\section{DEVELOPMENT TREND AND PROSPECT OF MoBILE PAYMENT IN ELECTRONIC COMMERCE}

\section{A. Future Development Trend of Mobile Payment}

Through the above analysis, the mobile payment is definitely an inevitable choice for the development of payment method, which has a larger development space in China. However, due to various reasons, it will experience a downturn or slow development period. Specifically, the development of mobile payment is shown as below:

\section{1) China's Mobile Payment has great potential}

Currently 616.017 million mobile phone users, 79.348 million broadband access users and their continued growth will provide a huge payment terminal node for mobile payment, and thus create a huge market for mobile payments.

2) The consumer's mobile payment habits still need cultivation.

Payment needs of consumers is an important driving force for the development of payment. The vast majority of mobile phone users are worried about the safety of mobile payment, and consumers have greater payment inertia towards the original payment method. Therefore, while solving the technical safety, it is essential to cultivate the mobile payment habits of consumers.

3) The telecom operators will continue to keep lowkey attitude towards the mobile payment in a short term.

Before the telecommunications restructuring and nonobvious various macroeconomic policies, any telecom operator will not act rashly to avoid more troubles, so the two, in the short term, they will still show a low-key attitude.

4) The development of mobile payment will definitely experience the process from micro-payment to lump-sum payment and from electronics product payment to in kind payment.

The nature of mobile payment determines that it will start from micro-payment and electronic product payment, yet it will transit to lump-sum and in kind payment after a certain degree of development. BMN,

\section{B. Suggestions on Future Development of Mobile Payment}

In the first quarter of 2010, China had 404 million Internet users and 780 million mobile phone users. Since the mobile payment shows increasingly obvious advantages, more and consumers will join the ranks of mobile payments. Based on satisfying people's transaction payment demands, currently all operators strive to realize self-interest maximization, and mobile payment becomes a very good operating highlight, providing a good 
development platform for the development of operators and consumer payment.

1) Expand the value-added business space

Vigorously develop the mobile value-added services, seek more payment points for mobile payment, bring more payment business, and attract more customers. Today, China's development space of mobile payment is not completely open, so according to the constant changes in domestic market and overseas market, the present domestic mobile payment service providers should try to develop the mobile payment value-added business in line with China's market economic demands as soon as possible, in order to improve the payment attraction to consumers;

2) Strengthen cooperations and complementarities between industries

Mobile payment is a comprehensive payment system involving multiple areas, so the development of mobile payment is inseparable from the industrial chain supports. For example, communications operators lack management experience in the payment process, which is precisely an advantage of financial institutions; the financial institutions have inadequate control over the transmission channels of mobile payment business, whereas the communications operators not only controls the transmission channel, but also owns huge mobile phone users. It is therefore necessary to strengthen cooperation between the various mobile payment forms, in order to promote the rapid development of mobile payment based on mutual benefits.

\section{3) Unified charging charges}

Unified charging standard is to make all payments under an orderly environment, have a complete viable payment system, and thus attract consumers based on improved trusts.

\section{CONCLUSION}

With the development of the times, people's living standards are improving, and various transaction activities are constantly emerging. In order to realize various financial transaction more effectively and easily, mobile payment come into being. Mobile payment is based on the mature development of Internet, computers and mobile communications technology, which has promoted the significant progress of the payment industry and occupied a favorable position in the payment industry by virtue of its strengths. At present, the mobile payment still has greater development space, not only effectively expanding the business scope, but also having spaces for further innovation and transformation in the payment technology. Therefore, although China's mobile payment is still in the development stage, it will have a promising development prospect..

\section{REFERENCES}

[1] Zhang Wei. Research on Mobile Payment and Management in Electronic Commerce in $3 \mathrm{G}$ era [D]. Beijing University of Posts and Telecommunications.2009, 06-03.

[2] Chen Yingyi. Research on Mobile Payment Development in Electronic Commerce [C]. China's Tobacco Electronic Commerce and Modern Logistics Development Forum. 2011, 12-01

[3] Gao Ming. Research on Mobile Payment in Electronic Commerce. Jiangxi University of Science and Technology. 2009, 06-12.

[4] Zhang Guilong. Research on Mobile Payment in Electronic Commerce. [D]. Tongji University. 2007, 08-04.

[5] Li Feng. Research on Mobile Payment Safety [D]. Shandong University. 2008, 12-29.

[6] Li Qingyan, Jin Duo, Zhang Wen'an, Zhang Tao. Research on Development Trend of Mobile Electronic Commerce [J]. Telecommunications Science. 2011, 27(6)

[7] Xu Luting. Presearch on Mobile Commerce and Safety Mobile Payment based on WAP2.0 [D]. Nanjing University for Information Science and Technology. 2007, 09-03

[8] Yue Yunkang. Research on Mobile Payment Problems in China's Electronic Commerce [J]. China Business and Market. 2008, 22(1).

[9] Wu Min, Xiong Xingping. Current Situation and Future Development of Mobile Payment [J]. China Business Update. 2011, (22).

[10] Li You. Comparative Analysis of Electronic Payment Method in China's Electronic Commerce [J]. Technological Development of Enterprise. 2006, 25(6)

[11] Xu Huimin. Research and Development of China's Mobile Payment Market [D]. Southwestern University of Finance and Economics. 2007, 07-02.

[12] ROCHET J C , TIROLE J . Two-sided Markets : An Overview[D]. conference on Two-Sided Markets, 2004, 3:68 -82 .

[13] P.Olla,N.Patd,C.Atkinson,A case study of mobile commerce:a frame work for creating mobile Internet systems.[J]Internet Research:Electronic Networking Applications and Policy 13(4)(2003)311 - 321.

[14] Draft Version.WAP Public Key Infrastructure Definition[Z].2001, 4-24.

[15] Julia Q. Zhu. China's electronic commerce goes mobile in 2014[J].Facebook. 2013,12-30. 